\title{
Optimizing management of natural and artificial matings in swine
}

\author{
W. L. Flowers and K. L. Esbenshade \\ Department of Animal Science, North Carolina State University, Raleigh, NC 27995-7621, USA
}

\begin{abstract}
A successful mating involves the coordination of many physiological events including insemination, gamete transport and ovulation. As more basic information about these processes becomes available, it is apparent that there are opportunities for manipulating these physiological events and enhancing the reproductive success of natural and artificial matings. The primary intent of this review is to examine the effectiveness of several of these strategies, as determined by their influence on farrowing rate and litter size. It is evident that the timing, duration and pattern of ovulation in pigs are extremely variable. Thus, increasing the frequency and changing the timing of matings during oestrus has received renewed interest. In general, if a female exhibits oestrus for more than 1 day, then increasing the frequency of matings has a greater influence on reproductive performance than does altering the timing of matings. In addition, litter size is more responsive to increased mating frequencies than is farrowing rate. Increasing the number of matings per oestrus via the use of combinations of natural service and artificial insemination, compared with the use of either alone, appears to enhance reproductive performance. It has been well documented that several aspects of the mating process itself can advance the onset of ovulation and enhance sperm transport and storage in the female reproductive tract. As a result, the use of these stimuli in conjunction with natural and artificial matings provide opportunities for enhancing fecundity. Pre- and postbreeding treatments with vasectomized boars, nonviable semen, oestrogens and seminal plasma have all been reported to increase farrowing rate and litter size. With artificial insemination, additions of prostaglandins, oxytocin, oestrogens and leucocytes to semen have been reported to enhance reproductive performance, albeit with varying degrees of success. Personnel and boar needs are important components in optimizing breeding management. Estimates of these needs for artificial and natural matings are discussed.
\end{abstract}

\section{Introduction}

From a reproductive standpoint, successful matings require the coordination of insemination with ovulation. From a management perspective, successful matings involve developing breeding strategies whereby successful matings occur in a cost effective manner. As a result, enhancement of physiological processes and reduction of production costs associated with mating are both key considerations for optimizing breeding management.

Swine producers have two types of matings from which to choose: natural service and artificial insemination. As more information concerning the basic physiology associated with breeding becomes available, it is apparent that there are opportunities for manipulating breeding-related events and enhancing the reproductive success of artificial and natural matings. The primary intent of this review is to 
examine the effectiveness of several of these strategies, as determined by their influence on farrowing rate and litter size.

In addition, since natural service and artificial insemination both involve significant financial investments, a secondary objective is to review labour and boar requirements associated with each type of mating. Consequently, the end result should be a summary of relevant reproductive and management data from which informed decisions concerning optimization of breeding management can be made.

\section{Enhancing Reproduction from Natural and Artificial Matings}

Many different management strategies have been used in conjunction with natural and artificial matings to enhance farrowing rate and litter size. Because all of these techniques are based on manipulating or enhancing some basic aspect of the breeding process, in a general sense, results obtained with those used with natural service should apply to artificial insemination and vice versa. However, there are some differences between the two mating systems, such as the number of spermatozoa inseminated; when appropriate, potential and observed differences in effectiveness will therefore be discussed.

\section{Frequency and timing of matings}

As stated earlier, an important aspect of optimizing breeding management is maximizing reproductive performance. This is achieved when the breeding scheme consistently creates a situation in which adequate numbers of viable spermatozoa are present in the oviduct before ovulation (Dziuk and Polge, 1965). For this to occur, insemination must be coordinated with ovulation. Thus, an understanding of ovulatory dynamics in swine is necessary.

It is generally accepted that ovulation in pigs begins $36-44 \mathrm{~h}$ after the onset of oestrus and lasts for 1-3 h. In addition, most follicles (68-95\%) appear to ovulate over a short time, while a minority ovulate over a longer time (Hunter, 1972; Pope et al., 1988). However, the onset and duration of ovulation are extremely variable (Table 1). This variation is perhaps best illustrated by the data of Weitze et al. (1992). in their study, the average duration from the onset of oestrus to ovulation for all females examined ( $n=$ 413) was $44.4 \mathrm{~h}$. However, the means of animals in the first and fourth quartiles were 26.2 and $57.9 \mathrm{~h}$, respectively - a difference of about $30 \mathrm{~h}$. On the basis of this information, it is clear that the variation associated with the ovulatory process is one of the critically important issues associated with optimizing reproduction from natural and artificial matings.

Table 1. Estimates of the onset and duration of ovulation in pigs

\begin{tabular}{lrcl}
\hline Ovulation & $\begin{array}{c}\text { Mean } \\
(\mathrm{h})\end{array}$ & $\begin{array}{c}\text { Range } \\
(\mathrm{h})\end{array}$ & \multicolumn{1}{c}{ Reference } \\
\hline Onset $^{b}$ & 41.7 & $30-45$ & $\begin{array}{l}\text { Signoret } \text { et al., 1972 } \\
\end{array}$ \\
& 37.6 & $23-48$ & Weitze et al., 1990a \\
& 47.5 & $17-68$ & Soede, 1992 \\
& 24.4 & $-2-50$ & Soede, 1992 \\
& 44.4 & $24-96$ & Weitze et al., 1992 \\
Duration & 2.0 & $1-3$ & Pitkjanen, 1958 \\
& 1.0 & $1-3$ & Betteridge and Raeside, 1962 \\
& 2.1 & $0.5-4$ & Signoret et al., 1972 \\
& 4.6 & $2-7$ & Soede, 1992 \\
& 1.8 & $0.8-3$ & Soede, 1992 \\
\hline
\end{tabular}

-Values either represent actual ranges reported or calculated ranges from the standard deviation ( \pm I standard deviation).

'Onset refers to the interval from the onset of oestrus to the initiation of ovulation. 
One way to cope with this variation is to alter the timing or frequency at which matings occur. Some information is available concerning the effect of mating fequency, but very little exists with regard to the influence of changing the timing of matings. Double matings were found to be superior to single matings in terms of litter size and conception rate (Domanski, 1966; Miljak et al., 1969; Flowers and Alhusen, 1992). From a summary of field observations, Reed (1982) reported that reproductive performance was improved when sows were mated three times during oestrus. Similarly, in a more controlled study, Tilton and Cole (1982) observed larger litters in triple- versus double-mated sows. In contrast, no differences were observed in litter size between sows that were mated twice on either the first or second day of oestrus (Tilton and Cole, 1982). These results indicate that increasing the frequency of mating increases reproductive performance, whereas changing the timing does not.

A more complete assessment of the effects of timing and frequency of matings is provided by data presented in Tables 2 and 3 (W. L. Flowers, unpublished). In this experiment, females were randomly assigned to receive morning or afternoon matings via artificial insemination $\left(5 \times 10^{9}\right.$ spermatozoa per mating) on either the first or second day of oestrus. Animals that exhibited oestrus for more than 3 days were excluded from the study. Allocation of animals in this manner resulted in a variety of treatments from which the effect of both timing and frequency of matings could be evaluated. Although data are still being collected, these results illustrate some important aspects concerning the influence of the frequency and timing of matings on reproductive performance.

Table 2. Effect of the timing and frequency of matings on reproductive performance of gilts at oestrus for 1 day

\begin{tabular}{lccc}
\hline Treatment & $n^{\mathrm{b}}$ & $\begin{array}{c}\text { Farrowing } \\
\text { rate (\%) }\end{array}$ & $\begin{array}{c}\text { Number of pigs } \\
\text { born alive }\end{array}$ \\
\hline Morning/ & 35 & $87.4 \pm 5.3$ & $8.5 \pm 0.3$ \\
/Afternoon & 36 & $85.3 \pm 3.8$ & $8.3 \pm 0.3$ \\
Morning and afternoon/ & 25 & $88.2 \pm 3.2$ & $8.7 \pm 0.3$ \\
\hline
\end{tabular}

Values are means \pm SEM.

'Day I/day 2; moming matings occurred between 07:00 and 09:30 $\mathrm{h}$ and afternoon matings occurred between 15:00 and 17:30 h.

'Number of gilts mated per treatment.

First, the effect of breeding frequency depends upon the duration of oestrus. In this study, if gilts were observed at oestrus for 1 day, then increasing the number of matings from one to two did not influence reproductive performance. However, if gilts exhibited a standing reflex for 2 days, then double matings increased both farrowing rate and litter size. Second, the number of pigs born alive is related more to multiple matings than is farrowing rate. This is evident in that litter size improved when mating frequency was increased from two to four times, whereas the percentage of animals that farrowed did not. Finally, it appears that mating frequency has more influence on reproductive performance than does the timing of matings. This was evident by the fact that if females were at oestrus for two days and mated more than once, morning and afternoon services produced equivalent results. In contrast, performance was improved by increasing mating frequency.

Although many explanations are possible, these data probably reflect the fact that the onset, timing and duration of ovulation vary considerably among animals even under conditions where management and genetics are held constant. Consequently, increasing the frequency of matings is an effective strategy for enhancing reproductive performance because no assumptions are made about the variability of the ovulatory process. Matings are distributed evenly throughout the duration of oestrus so that one or more matings coincide with ovulation. In contrast, changing the timing of matings is less effective because matings are concentrated during a predetermined period during which ovulation is anticipated. If ovulation occurs during this period, then reproduction is maximal. However, if it does not, then farrowing rate and litter size are lower. 
Table 3. Effect of the 'timing and frequency of matings on reproductive performance of gilts at oestrus for 2 days

\begin{tabular}{|c|c|c|c|}
\hline Treatment ${ }^{2}$ & $n^{b}$ & $\begin{array}{l}\text { Farrowing } \\
\text { rate }(\%)\end{array}$ & $\begin{array}{c}\text { Number of pigs } \\
\text { born alive }\end{array}$ \\
\hline Aftemoon/ & 65 & $72.3 \pm 4.6^{\circ}$ & $8.0 \pm 0.2^{c}$ \\
\hline /Morning & 68 & $74.3 \pm 3.8^{\mathrm{c}}$ & $8.0 \pm 0.3^{c}$ \\
\hline Morning/moming & 80 & $86.4 \pm 3.5^{\mathrm{d}}$ & $8.6 \pm 0.2^{\mathrm{d}}$ \\
\hline Afternoon/morning & 84 & $85.7 \pm 4.1^{\mathrm{d}}$ & $8.7 \pm 0.2^{\mathrm{d}}$ \\
\hline Morning and afternoon/moming & 67 & $87.5 \pm 5.3^{\mathrm{d}}$ & $8.9 \pm 0.3^{\mathrm{de}}$ \\
\hline Afternoon/morning and afternoon & 72 & $86.5 \pm 4.6^{d}$ & $8.8 \pm 0.2^{\mathrm{de}}$ \\
\hline $\begin{array}{l}\text { Morning and aftemoon/ } \\
\text { morning and afternoon }\end{array}$ & 78 & $88.7 \pm 5.1^{d}$ & $9.2 \pm 0.2^{e}$ \\
\hline
\end{tabular}

Values are means \pm SEM.

'Day 1/day 2; moming matings occurred between $07: 00$ and $09: 30 \mathrm{~h}$ and afternoon matings occurred between 15:00 and 17:30 h.

'Number of gilts mated per treatment.

Means without a common superscript in the same column are significantly different $(P<0.05)$.

The only exception to this rationale would be the situation in which females are at oestrus for short periods. In this case, the variation associated with the ovulatory process may be reduced owing to the shorter duration of oestrus (Soede, 1992). Consequently, a single mating, regardless of its timing, may be sufficient to ensure optimal reproduction.

Because the timing, duration and pattern of ovulation are highly variable among animals within the same herd, these parameters also probably vary substantially among herds. Evidence for this is shown (Table 1). This observation accounts for differences among herds in response to alterations in the frequency and timing of matings.

\section{Combinations of natural and artificial matings}

The use of artificial insemination in conjunction with natural service is one approach that has been used to increase mating frequency and enhance reproductive performance. Several recent studies have reported that combinations of natural and artificial matings, compared with the use of either alone, improve farrowing rates and litter size (Hooper et al., 1986; Hooper and Green, 1990; Flowers and Alhusen, 1992). Reasons for this observation have not been critically evaluated, but the following explanations have been proposed. For the purposes of this discussion, combination matings will refer to the situation in which sows are mated at the first detected oestrus via natural service and all subsequent matings are supplied by artificial insemination.

Flowers and Alhusen (1992) suggested that artificial insemination may be more advantageous than natural service in certain situations. On the basis of increases in concentrations of corticosteroids during copulation, it has been proposed that many of the activities associated with natural matings in swine represent a form of stress for sows and gilts (Liptrap, 1970; Barnett et al., 1982). Consequently, artificial insemination may be less stressful to the sow or gilt because she is not exposed to extreme courting episodes of the boar or required to support his weight during mating (Flowers and Alhusen, 1992). This notion seems plausible since the greatest increases in reproductive performance owing to combination matings are usually observed with gilts - a situation where size differences among animals are likely to be large (Flowers and Alhusen, 1992) and when mating frequency is high - a situation where interactions with the boar are increased (Hooper et al., 1986). Obviously, relationships between the type of mating, stress inherent to the breeding process and reproductive performance warrant further investigations. However, if there are negative relationships, this could account for the observed superiority of combination matings compared with exclusively natural service. 
Conversely, detection of oestrus is inherently more difficult with artificial insemination than with natural service (Melrose, 1966; Polge, 1978; Reed, 1982). As a result, more errors in determination of the onset of oestrus and, thus, the occurrence of matings relative to ovulation are probably made when mating artificially compared with naturally. When this situation occurs, reproductive performance is reduced (Dziuk and Polge, 1965; Polge, 1978). Because the oestrus detection component in combination matings is supplied via natural service, more accurate determination of the onset of oestrus could be one reason why reproductive performance has been reported to be better with combination than in exclusively artificial matings. In essence, combination matings, in certain situations, may be physiologically more advantageous than natural service and technically more accurate than artificial insemination. As a result, enhancement of reproduction would be expected.

\section{Administration of pre-and post-mating treatments}

In addition to spermatozoa, other components of the mating process are required for optimization of farrowing rates and litter size (Claus, 1990). This is due to the fact that many of the stimuli associated with mating influence important physiological events necessary for successful reproduction. For example, Signoret et al. (1972) reported that coitus reduced the duration and hastened the onset of ovulation. Similarly, Weitze et al. (1990a) advanced the ovulatory process by $14.4 \mathrm{~h}$ with infusions of seminal plasma. Although the exact mechanisms are not known, it has been proposed that the physical manipulation of the cervix (Guthrie et al., 1972; Ziecik et al., 1981), seminal oestrogens (Claus, 1990) and other components of seminal plasma (Weitze et al., 1990b,c; Willmen et al., 1991) are responsible for this phenomenon. In addition, these same stimuli have been shown to influence sperm transport via stimulation of myometrial contractions (Claus et al., 1989a; Claus, 1990; Weiler and Claus, 1991). Consequently, administration of these stimuli in conjunction with the mating process are physiologically reasonable ways to enhance reproductive performance.

The effectiveness of administering these stimuli before a single natural mating or a combination of natural and artificial matings is illustrated in Table 4 (W. L. Flowers and K. L. Esbenshade, unpublished). The oestrogen solution contained physiological amounts of oestrogens similar to those found in boar semen (Claus et al., 1987). The seminal plasma was collected from vasectomized males and contained considerably lower oestrogen concentrations (13\%) than those normally present in the semen from intact boars. Cervical stimulation consisted of infusion of Beltsville Thawing Solution semen extender (Pursel and Johnson, 1975) via an artificial insemination catheter. Prebreeding treatments were administered once, $20 \mathrm{~min}$ before mating on the first day of oestrus. Only information from females that exhibited oestrus for two days was analysed.

Seminal plasma was the only treatment that significantly increased reproductive performance. It is important to note that the average level of performance in the experimental herd was good. This is evident from the fact that farrowing rate and litter size for the control group were greater than $87 \%$ and ten pigs were born alive, respectively. Thus, in this situation, administration of seminal plasma improved reproductive performance that was already, perhaps, close to optimal.

Consequently, reproductive performance from sows mated only once provides a better biological assessment of the effectiveness of these mating-related stimuli because each was applied in a situation where reproductive performance was expected to be reduced. From these data, it was apparent that seminal oestrogens and seminal plasma enhanced farrowing rates, but not litter size, whereas cervical stimulation appeared to have little or no effect on either production variable. However, it is important to note that none of the prebreeding treatments could substitute for a mating containing spermatozoa on the second day of oestrus. One possible explanation for this observation is that both seminal oestrogens and seminal plasma did influence ovulation and sperm transport to some extent, but either the timing or magnitude of these treatments, relative to mating, was not sufficient to control the occurrence or duration of the ovulatory process completely.

Results (summarized in Fig. 1) provide information that, at least, partially addresses this possibility (W. L. Flowers and K. L. Esbenshade, unpublished). Experimental procedures were the same as described previously except treatments were administered $24 \mathrm{~h}$ after natural service. In one herd, seminal oestrogens, but not cervical stimulation or seminal plasma, produced reproductive performance equivalent to 
Table 4. Effect of prebreeding treatments on reproductive performance of sows

\begin{tabular}{|c|c|c|c|}
\hline Treatment ${ }^{2, b}$ & $n^{\mathrm{c}}$ & $\begin{array}{l}\text { Farrowing } \\
\text { rate (\%) }\end{array}$ & $\begin{array}{c}\text { Number of pigs } \\
\text { born alive }\end{array}$ \\
\hline None/NS/Al & 119 & $88.3 \pm 2.7^{\mathrm{d}}$ & $10.6 \pm 0.3^{\mathrm{d}}$ \\
\hline BTS/NS/AI & 117 & $84.6 \pm 3.5^{\mathrm{d}}$ & $10.5 \pm 0.4^{\mathrm{d}}$ \\
\hline $\mathrm{E}_{2} / \mathrm{NS} / \mathrm{Al}$ & 120 & $87.1 \pm 3.8^{\mathrm{d}}$ & $10.6 \pm 0.3^{d}$ \\
\hline $\mathrm{SP} / \mathrm{NS} / \mathrm{Al}$ & 125 & $94.6 \pm 2.4^{\mathrm{e}}$ & $11.4 \pm 0.3^{e}$ \\
\hline BTS/NS/none & 86 & $72.6 \pm 2.9$ & $8.7 \pm 0.4^{f}$ \\
\hline $\mathrm{E}_{2} / \mathrm{NS} /$ none & 76 & $79.7 \pm 4.0^{8}$ & $9.0 \pm 0.3^{f}$ \\
\hline SP/NS/none & 79 & $81.4 \pm 3.2^{8}$ & $9.0 \pm 0.3^{f}$ \\
\hline None/NS/none & 92 & $70.3 \pm 3.9^{4}$ & $9.1 \pm 0.4^{\mathrm{f}}$ \\
\hline
\end{tabular}

\footnotetext{
Values are means \pm SEM.

-Pre-mating treatment/day $1 /$ day 2.

bS: natural service; Al: artificial insemination; BTS: Beltsville Thawing Solution (Pursel and Johnson. 1975); $E_{2}$ : oestrogens; SP: seminal plasma from vasectomized boars.

Number of sows mated in each treatment.

drigeans within the same column without common superscripts are significantly different $(P<0.05)$.
}

that of two natural matings. In contrast, in another herd, these same treatments had no influence on reproductive performance. (These data represent results from two separate studies that were conducted on different farms under common ownership. As a result production variables such as nutrition, genetics, equipment and routine management procedures were similar.)

Collectively, these results indicate that administration of solutions composed of oestrogens or seminal plasma before or after mating can influence the birth of live offspring. However, the timing of their administration relative to a mating containing spermatozoa, among other unidentified factors, determines the magnitude of the response. In general, seminal plasma is effective when given before matings, whereas the opposite appears to be true for seminal oestrogens.

An important point to consider is that every time a female is mated naturally, she presumably receives a full complement of these mating-related stimuli. In contrast, with artificial insemination, concentrations of seminal oestrogens and other compounds in seminal plasma are reduced because semen is normally diluted 20-30 times. Thus, pre- and post-breeding treatments may be more important for optimizing reproduction with artificial than with natural matings. Some evidence for this concept is provided by the observations of Willmen et al. (1991), who observed an interaction between insemination dose and seminal plasma pretreatment. In this study, the relative difference in fertilization rates between control and treated animals increased as the insemination dose decreased. Similar relationships were observed by Rath et al. (1989). However, contemporary comparisons between animals receiving seminal plasma and mated via either natural service or artificial insemination are required to evaluate this hypothesis critically.

Another way to administer seminal plasma and cervical stimulation in conjunction with natural and artificial matings is through the use of vasectomized boars. Mah et al. (1985) observed an increase in conception rate in females that were mated to a vasectomized boar following natural service, whereas farrowing rates were improved in herds using artificial insemination when vasectomized males were allowed to mate with oestrous females before insemination (Glossop, 1992). Again, it is interesting to note that the magnitude of the observed improvement in conception rate was greater when used in conjunction with artificial insemination than with natural service. Whether this observation is related to the timing of the vasectomized mating or is unique to its use in conjunction with artificial insemination is not known.

In addition to peri-mating stimuli, administration of substances several days or weeks before mating have been reported to improve fecundity in swine. The rationale behind this strategy is based on the 

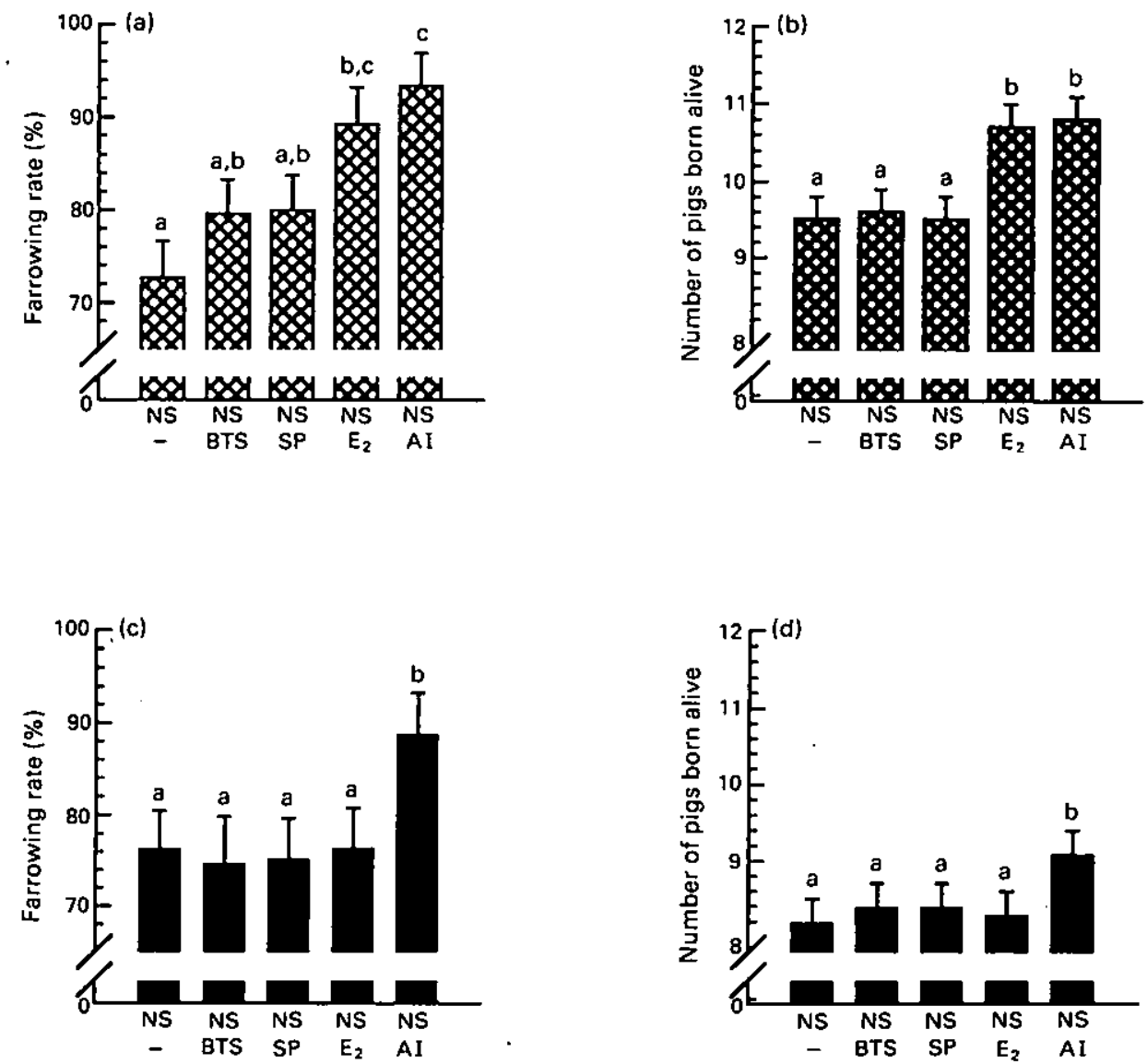

Fig. 1. Effect of post-mating stimuli on reproductive performance of sows in two different herds: (a) farrowing rate in herd 1; (b) number of pigs bom alive in herd 1; (c) farrowing rate in herd 2; and (d) number of pigs born alive in herd 2 . Treatments were administered $24 \mathrm{~h}$ after a natural mating on the first day of oestrus. NS: natural service; $E_{2}$ : oestrogens; SP: seminal plasma; Al: artificial insemination; BTS: Beltsville Thawing Solution (Johnson and Pursel, 1975). Means without common superscripts are significantly different $(P<0.05)$.

hypothesis that the immune system of the female may influence litter size by destroying spermatozoa deposited in the female reproductive tract during mating (Veselky et al., 1981). Although primary humoral responses to spermatozoa are not induced in the female by mating, it has been suggested that some limited cellular responses might occur (Hancock, 1981; Matousek, 1985). In addition, seminal plasma appears to exert various degrees of immunosuppressive activity (Stanek ef al., 1985; Koch and Ellendorff, 1985).

Results from these types of study are equivocal. Murray et al. (1983) and Murray and Grifo (1986) observed increases in litter size when gilts were infused with nonviable semen one oestrous cycle before a fertile mating. Furthermore, sterile matings with vasectomized boars for several oestrous periods before exposure to intact males have been reported to increase fecundity in gilts (Aheme, 1992; Friendship et al., 1992). However, this response appears to vary considerably. In contrast, in more controlled studies, no effect of seminal plasma or nonviable semen was observed when it was used as a prebreeding treatment either at weaning in sows or during the preceding oestrus in gilts (Giles et al., 1990). It has been proposed that immunosuppressive mechanisms provided by seminal components are of limited effectiveness in swine because semen is deposited into the uterus (Claus, 1990). 
Additions to semen used in artificial insemination

Another strategy used to enhance reproductive performance of artificial matings is the addition of various compounds to extended semen. Most of these substances enhance some aspect of the breeding process and, thus, should improve fecundity. Oxytocin and its analogues and $\mathrm{PGF}_{2 \alpha}$ stimulate sperm transport by increasing myometrial contractions (Challis and Lye, 1986), whereas leucocytes, in theory, enhance the immune system in the female reproductive tract (Hancock, 1981). Oestrogens have been shown to influence both myometrial activity and the timing of the preovulatory LH surge (Claus, 1990).

The effectiveness of additions of these compounds to semen are summarized (Table 5). In general, it appears that most are either not effective or mildly stimulatory. In the studies that reported dramatic increases in performance, control levels of reproductive performance with artificial insemination were usually low, which probably indicates correction of procedural problems rather than a true enhancement of breeding physiology. In several cases, the magnitude of the response was quite variable among farms or groups of females on the same operation. The reasons for the limited effectiveness of these compounds when administered with spermatozoa during insemination are not clear.

Table 5. Effect of addition of various compounds to pig semen on farrowing rate and litter size

\begin{tabular}{|c|c|c|c|}
\hline Additive & $\begin{array}{c}\text { Change in } \\
\text { farrowing } \\
\text { rate }^{4}\end{array}$ & $\begin{array}{l}\text { Change in } \\
\text { litter } \\
\text { size }\end{array}$ & Reference \\
\hline \multirow[t]{4}{*}{ Leucocytes } & n.r. & $+12.0 \%$ & Skjervold et al., 1979 \\
\hline & n.r. & $+12.0 \%$ & Almid, 1981 \\
\hline & n.r. & +0.1 pigs & Blichfeldt, 1984 \\
\hline & n.r. & -0.3 pigs & Van der Lende et al., 1986 \\
\hline \multirow[t]{4}{*}{ Oestrogens } & $+5.7 \%$ & +0.5 pigs & Claus et al., 1989b \\
\hline & $-1.0 \%$ & -0.2 pigs & Lambert et al., 1991 \\
\hline & $+12.0 \%$ & n.r. & Kirkwood and Thacker, 1991 \\
\hline & $+5.0 \%$ & +0.1 pigs & Kirkwood and Thacker, 1991 \\
\hline \multirow{5}{*}{$\begin{array}{l}\text { Oxytocin and } \\
\text { its analogues }\end{array}$} & & & \\
\hline & $+1.8 \%$ & +0.1 pigs & Krajnak, 1988 \\
\hline & $-4.2 \%$ & -0.2 pigs & Krajnak, 1988 \\
\hline & $+4.8 \%$ & +0.3 pigs & Odehnal et al., 1990 \\
\hline & $+17.1 \%$ & n.r. & Paig ef al., 1992 \\
\hline Prostaglandins & $+14.1 \%$ & n.r. & Niwa ef al., 1982 \\
\hline
\end{tabular}

'Change relative to control treatments (no additive). n.r.: Not reported.

\section{Reducing Management Costs Associated with Breeding}

In addition to enhancing fecundity, optimization of breeding management also involves reduction of management costs associated with breeding. Some costs associated with breeding are difficult to evaluate without subjectivity and, thus, make comparisons among different breeding strategies difficult. However, two of the major expenditures, boars and labour, have been estimated objectively (Flowers and Alhusen, 1992) and provide the opportunity to make direct comparisons between breeding systems using artificial insemination and natural service.

\section{Labour and boar requirements}

Estimates of labour requirements for natural and artificial matings are shown in Tables 6 and 7 (Flowers and Alhusen, 1992). In general, these data indicate that the amount of time required per mating is 
based on both daily breeding demands and the type of mating administered. This is due to the fact that collection and processing of semen require considerably more time than do other routine activities unique to artificial insemination and are independent of daily breeding demands. Consequently, as the number of sows and gilts bred from a single ejaculate increases, 'the amount of time required for collection and processing decreases on a per animal basis. In this particular study, any time four or more females needed to be mated, artificial insemination significantly reduced the amount of time required for mating. It is important to note that in this study insemination doses contained $7 \times 10^{9}$ spermatozoa instead of the customary $2-3 \times 10^{9}$. The relative advantage of artificial insemination compared with natural service observed is therefore an underestimate of what could be accomplished in production situations.

Although it has not been critically evaluated, boar requirements for artificial insemination should logically be less than those for natural service because an average ejaculate usually produces $15-20$

Table 6. Mean time $( \pm S E)$ required per animal to perform routine activities associated with natural service and artificial insemination in pigs ${ }^{\mathbf{a}}$

\begin{tabular}{lr}
\hline Routine activity & $\begin{array}{c}\text { Time required } \\
\text { (min) }\end{array}$ \\
\hline Natural service $^{\text {Detection of oestrus }}{ }^{\mathrm{b}}$ & \\
$\quad$ Supervision of mating $^{\mathrm{b}}$ & $9.7 \pm 1.2$ \\
Artificial insemination $^{\mathrm{c}}$ & $12.3 \pm 1.5$ \\
Detection of oestrus $^{\mathrm{c}}$ & $9.2 \pm 1.6$ \\
Collection of semen $^{\mathrm{d}}$ & $11.3 \pm 2.0$ \\
Processing of semen $^{\mathrm{d}}$ & $6.7 \pm 0.8$ \\
lnsemination $^{\mathrm{c}}$ & $3.4 \pm 1.5$ \\
Equipment cleaning $^{\mathrm{d}}$ & $3.1 \pm 0.5$ \\
\hline
\end{tabular}

'Data from Flowers and Alhusen, 1992.

'Means based on observations from 393 natural matings performed on sows. 'Means based on observations from 341 natural matings performed on sows. 'Means based on 118 semen collections.

Table 7. Mean ( $\pm \mathrm{SE})$ time (min) required per sow to perform routine activities associated with natural and artificial matings based on daily breeding demands $\mathbf{s}^{\mathrm{a}}$

\begin{tabular}{ccc}
\hline $\begin{array}{c}\text { Number of animals } \\
\text { mated per day }\end{array}$ & $\begin{array}{c}\text { Natural } \\
\text { service }^{b}\end{array}$ & $\begin{array}{c}\text { Artificial } \\
\text { insemination }\end{array}$ \\
\hline 1 & $23.4 \pm 1.7^{*}(19)$ & $34.6 \pm 2.1(13)$ \\
2 & $24.4 \pm 2.0(18)$ & $25.7 \pm 2.1(13)$ \\
3 & $24.7 \pm 1.5(22)$ & $21.7 \pm 1.1(19)$ \\
4 & $24.1 \pm 1.2^{*}(37)$ & $19.8 \pm 1.1(28)$ \\
5 & $23.4 \pm 1.1^{*}(25)$ & $18.9 \pm 0.9(29)$ \\
6 & $23.9 \pm 1.6^{*}(15)$ & $18.0 \pm 1.1(10)$ \\
7 & $22.9 \pm 1.8^{*}(12)$ & $17.6 \pm 1.1(10)$ \\
8 & $22.8 \pm 1.4^{*}(10)$ & $17.3 \pm 1.0(6)$ \\
\hline
\end{tabular}

Data from Flowers and Alhusen, 1992.

"Numbers in parentheses are numbers of observations per treatment.

*Significantly different from artificial insemination $(P<0.05)$. 
Table 8. Reproductive performance and estimates of labour and boar requirements for combinations of natural service (NS) and artificial insemination (Al) in pigs $^{\mathrm{a}}$

\begin{tabular}{lccc}
\hline Variable $^{\mathrm{bc}}$ & NS/NS & NS/AI & NS + NS/NS \\
\hline Farrowing rate (\%) & $88.5 \pm 4.7$ & $93.2 \pm 3.2$ & $89.4 \pm 3.5$ \\
Number of pigs born alive & $10.2 \pm 0.3$ & $10.3 \pm 0.3$ & $10.5 \pm 0.2$ \\
Labour per sow (min) & $35.6 \pm 5.1^{\mathrm{d}}$ & $24.6 \pm 4.2^{\mathrm{e}}$ & $50.4 \pm 7.1^{\mathrm{t}}$ \\
Number of ejaculates per sow & 2.0 & 1.1 & 3.0 \\
Pigs produced per h of labour & $15.2 \pm 3.0^{\mathrm{d}}$ & $23.5 \pm 3.8^{\mathrm{e}}$ & $11.2 \pm 3.6^{\mathrm{d}}$ \\
Pigs produced per ejaculate & $4.5 \pm 1.5^{\mathrm{d}}$ & $8.7 \pm 1.2^{\mathrm{e}}$ & $3.1 \pm 2.0^{\mathrm{d}}$ \\
\hline
\end{tabular}

Values are means $\pm \mathrm{SEM}$.

'W.L. Flowers, unpublished observations.

'Means represent observations from 300 sows in each treatment.

'Day 1 morning and afternoon/Day 2 morning; NS: natural service; AI: artificial insemination.

Means in the same row without common superscripts are significantly different $(P<0.05)$.

insemination doses (Reed, 1982). Consequently, a similar relationship as that observed for labour requirements probably exists between daily breeding demands and boar needs - as daily breeding demands increase, so does the relative advantage of artificial insemination compared with natural service in terms of number of boars required for mating.

Many factors unique to individual production situations such as the normal return (to oestrus) profile of weaned sows, the physical arrangement of breeding facilities and boar usage patterns influence labour and boar requirements. Consequently, absolute values for these production variables are likely to vary among operations. However, the relative advantages discussed should still apply since they are based on procedural differences between the two types of matings.

\section{Conclusions - Optimizing Breeding Management}

As stated earlier, optimization of breeding management involves maximizing reproductive performances first and reducing associated management costs. On the basis of the information provided in this review, there are a number of different ways to accomplish this goal. Regardless of the approach, these strategies can be evaluated with some degree of objectivity. To accomplish this, information with regard to reproductive performance needs to be evaluated in conjunction with production expenditures such as labour and boar requirements. This can be done by evaluating the number of pigs produced on a per ejaculate or per hour of labour basis. Expression of data in this manner is preferred because it allows comparisons to be made among situations that may differ in hourly wage of employees and boar usage.

Examples of these calculations are presented in Table 8. In this situation, two different strategies for optimizing reproductive performance were evaluated - increasing the mating frequency and combinations of natural service and artificial insemination. In this particular situation, optimization of breeding management, as defined previously, occurred with natural service followed by artificial insemination.

The authors thank the National Pork Producers Council for funding to support the authors and their research and several commercial swine farms on which many of the studies were conducted.

\section{References}

Aherne F (1992) On-farm test boosts use of "did" boars Intenational Piglester 1248

Almid T (1981) Does enhanced antigenicity of semen increase the litter size in pigs? Zeitschrift Fur Tierzuchthygiente und Zuchlungsbiologie 98 1-10
Barnett Jl. Hemsworth PH and Cronin GM (1982) The effect of mating on plasma corticosteroids in the female pig and the influence of individual and group housing on this response General and Comparative Endocrinology 47 516-529 
Betteridge KJ and Raeside JI (1962) Observation of the ovary by peritoneal cannulation in pigs Research in Veterinary Science 3 390-398

Blichfeldt T (1984) Effect of addition of antigen, adjuvant or mitogen to semen on embryonic survival in artificially inseminated gilts Zeitschriff Fur Tierzuchthygiene und Zuchtungsbiologie 101 298-304

Challis JRG and Lye SJ (1986) Parturition Oxford Reviews of Reproductive Biology 8 101-105

Claus R (1990) Physiological role of seminal components in the reproductive tract of the pig Jounal of Reproduction and Fertility Supplement 40 117-131

Claus R, Hoang-Vu C, Ellendorff F, Meyer HD. Schopper D and Weiler $U$ (1987) Seminal oestrogens in the boar: origin and functions in the sow Jounal of Steroid Biochemistry 27 $33 I-335$

Claus R, Ellendorff F and Hoang- $V_{u} C$ (1989a) Spontaneous electromyographic activity throughout the cycle in the sow and its charge by intrauterine oestrogen infusion during oestrus Joumal of Reproduction and Fertility 87 543-551

Claus R, Moshammer T, Aumuller R and Weiler U (1989b) Replenishment of Al-doses with oestrogens in physiological amounts: effect on sow prolificacy in a field trial joumal of the Veterinary Medical Association 36 797-800

Domanski J (1966) Effect of the time of the repeat mating in a double mating system on the fertility of the sow Zeszyly Problemowe Postep Nank Rolniczych 67 113-116

Dziuk PJ and Polge C (1965) Fertility in gilts following induced ovulation Veterinary Record 77 236-242

Flowers WL and Alhusen HD (1992) Reproductive performance and estimates of labor requirements associated with combinations of artificial insemination and natural service foumal of Animal Science 70 615-621

Friendship RM, Doig GS, Wilson MR and Hacker RR (1992) Evaluation of techniques to improve gilt reproductive performance Proceedings of the Inienational Pig Veterinary Society 12th Congress p 461. Royal Netherlands Veterinary Association, Boxel

Giles JR, Thompson LH Arkins S, Camacho $T$ and Eichen PA (1990) Effects of uterine infusion of nonviable semen, seminal plasma or egg albumen prior to breeding on the reproductive efficiency of gilts and sows Canadian jountal of Animal Science 70 129-133

Glossop CE (1992) The role of the vasectomised boar in enhancing fertility with Al Proceedings of the Intentational Pig Veterinary Society 12th Congress p 432. Royal Netherlands Veterinary Association, Boxel

Guthrie HD, Hendricks DM and Handlin DL (1972) Plasma oestrogen, progesterone and luteinizing hormone prior to estrus and during early pregnancy in pigs Endocrinology 91 675-679

Hancock RJT (1981) Immune responses to sperm Oxford Reviews of Reproductive Biology 3 182-208

Hooper PR and Green CG (1990) Two combined AI and natural service mating treatments compared Proceedings of the Intemational Pig Veterinary Society Ith Congress $p 467$. Swiss Association of Swine Medicine, Berme

Hooper PR, Green CG and Walters JR (1986) Aspects of commercial pig AI fertility levels Proceedings of the Intenational Pig Veterinary Society 9ih Congress p 15. Departmento de Prensa y Publicaciones, Barcelona

Hunter RHF (1972) Ovulation in the pig: timing of the response to injection of human chorionic gonadotropin Research in Veterinary Science 13 356-361
Kirkwood RN and Thacker PA (1991) The influence of adding estradiol to semen on reproductive performance of sows Canadian Joumal of Animal Science 71 589-591

Koch E and Ellendorff F (1985) Detection of activity similar to that of early pregnancy factor after mating sows with a vasectomized boar joumal of Reproduction and Fertility $\mathbf{7 4}$ 39-46

Krajnak P (1988) The effect of oxytocin added to insemination doses on fertility of pigs Pig News and Infonnation 11388 (Abstract)

Lambert EH, Williams DH, Lynch PB, Hanrahan TJ, McGready TA, Austin FH, Boland MP and Roche JF (1991) The effects of administration of gonadotropins and estrogens on prenatal survival in gilts Theriogenology 36 77-85

Liptrap RM (1970) Effect of corticotropin and corticosteroids on oestrus, ovulation and oestrogen secretion in the sow Joumal of Endocrinology 47 197-206

Mah J, Tilton JE, Williams GL, Johnson JN and Marcello MJ (1985) The effect of repeated mating at short intervals on reproductive performance of gilts joumal of Animal Science $601052-1054$

Matousek J (1985) Biological and immunological roles of proteins in the sperm of domestic animals (review) Animal Reproduction Science 8 I-40

Melrose DR (1966) Artificial insemination of pigs - a review of progress and possible developments World Review of Animal Production 11 15-26

Miljak N, Standovic F, Laktic Z and Herak M (1969) Results of examination of oestrous sows and gilts four times daily for the optimum time of insemination Veterinarsky Glasnik 23 185-190

Murray FA and Grifo AP, Jr (1986) Intrauterine infusion of killed semen to increase litter size in gilts foumal of Animal Srience 62 187-190

Murray FA, Grifo AP, Jr and Parker CF (1983) Increased litter size in gilts by intrauterine infusion of seminal and sperm antigens before breeding Joumal of Aumal Science 56 895-900

Niwa T. Hashizume T, Togashi $M$ and Konda $T$ (1982) Influences of addition of prostaglandin $\mathrm{F}_{2}$-alpha to boar semen diluent upon viability of sperm, conception rate and achievement of piglets Proceedings of the Interiational Pig Veterinary Society 7 th Congress $\mathrm{p} 216$. Associacion Intemacional de Vetemavios Especialistas en Cerdos, Mexico City

Odenhal F, Barth T and Jost K (1990) The effect of Depotocino (carbetocin) added to insemination doses of boar semen on the conception rate of sows and their fertility Pig News and Information 11203 (Abstract)

Paig JM, Genis MT and Crespo JA (1992) Parturition rate improvement in a closed herd using DECOMOTON $R$ in semen for artificial insemination (AI) Proceedings of the international Pig Veterinary Sociely $12 \mathrm{th}$ Congress p 441. Royal Netherlands Veterinary Association, Boxel

Pitkjanen IG (1958) The time of ovulation in sows Svinovortstoo $1238-40$

Polge $C$ (1978) Fertilization in the pig and horse Journal of Reproduction and Fertility 54 461-474

Pope WF, Wilde MH and Xie S (1988) Effect of electrocautery of nonovulated day 1 follicles on subsequent morphological variation among day 11 porcine embryos Biology of Reproduction 39 882-887

Pursel VG and Johnson LA (1975) Freezing of boar spermatozoa: fertilizing capacity with concentrated semen in a new thawing procedure Joumal of Animal Science $\mathbf{4 0}$ 99-105 
Rath D, Weitze KF, Pena Alfaro CE and Andrade Moura JC (1989) Effects of seminal plasma on the number of accessory sperm cells and fertilization in gilts Zuchthygiene 24 123-127

Reed HCB (1982) Artificial insemination. In Control of Pig Reproduction pp 65-90 Ed DJA Cole and GR Foxcroft. Butterworths, London

Signoret JP, du Mesnil du Buisson F and Mauleon P (1972) Effect of mating on the onset and duration of ovulation in the sow Joumal of Reproduction and Fertility 31 327-330

Skjervold H, Almid T, Onstad O and Fossum K (1979) Evidence of immunological influence on the number of live embryos in pigs Zeitschrift Fur Tierzuchthygiene und Zuchtongsbiologie $96235-236$

Soede NM (1992) Influcence of Insemination Conditions on Early Pregnancy in Pigs, with Emphasis on Embryonic Diversily PhD Thesis. Agricultural University, Wageningen

Stanek R, Veselky I, Dostal J and Sedlakavo M (1985) Effect of boar seminal plasma and seminal vesicle fluid on porcine lymphocytes Archives of Andrology 15 29-32

Tilton JE and Cole DJA (1982) Effect of triple versus double mating on sow productivity Animal Production 34 279-282

Van der Lende T, Donker $R$ and Hazeleger W (1986) Embryonic survival in the pig after insemination with antigen-enriched semen Theriogenology 26 391-396

Veselsky L, Stanek R and Hradecky J (1981) Effect of antibodies to boar spermatozoa on fertility in sows and rabbits Archives of Andrology 7 337-342

Weiler $U$ and Claus $R$ (1991) Endocrine aspects of testicular function, especially hormones in seminal plasma, and their fate in the female reproductive tract: testicular steroids and their relevance for male and female reproductive functions Reproduction in Domestic Animals Supplement 1 41-64

Weitze KF, Rath D, Willmen T, Waberski D and Lotz J (1990a) Advancement of ovulation in the sow related to seminal plasma application before insemination Reproduction in Domestic Animals 25 61-67

Weitze KF, Rabeler J, Willmen T and Waberski D (1990b) Interaction between inseminate, uterine and ovarian function in the sow 1. Influence of seminal plasma and oestrogens in the inseminate on intragenital sperm transport, time of ovulation and fertility results in gilts Reproduction in Domestic Animals 25 191-196

Weitze KF, Lotz J, Everwand A, Willmen T and Waberski D (1990c) Interaction between inseminate, uterine and ovarian function in the sow II. Investigations into the influencing of ovulation by the use of sperm free media Reproduction in Domestic Animals 25 197-204

Weitze KF, Wagner-Rietschel $\mathbf{H}$ and Richter L. (1992) Standing heat and ovulation in a sow herd. In Proceedings of the international Pig Veterinary Society 12th Congress pp 460 Royal Netherlands Veterinary Association, Boxel

Willmen T, Rabeler J. Everwand D and Weitze KF (1991) Influence of seminal plasma and oestrogens in the inseminate on fertilization rate, sperm transport and ovulation time Reproduction in Dontestic Animals Stoplement 1 379-383

Ziecik A, Tilton JE and Williams GL. (1981) Effect of mating on the luteinizing hormone surge in the pig Jounal of Animal Science 53 434-438 